\section{MEAN PLATELET VOLUME IN NEONATAL SEPSIS}

doi:10.1136/archdischild-2012-302724.1179

'MY Oncel, 'R Ozdemir, 'S Yurttutan, 'FE Canpolat, '0 Erdeve, 'SS Oguz, 'N Uras, 1,2U Dilmen. ' Neonatology, Zekai Tahir Burak Maternity Teaching Hospital; ${ }^{2}$ Pediatrics, Yıldırım Beyazıt University, Faculty of Medicine, Ankara, Turkey

Background and Aim The aim of this study was to investigate any changes in mean platelet volume (MPV) in patients with neonatal sepsis (NS)

Methods Consecutive newborns diagnosed with sepsis between March and July 2011 were included in the study. Subjects were stratified into two groups; proven sepsis (Group 1a) and clinical sepsis (Group 1b). The control group (Group 2) consisted of healthy newborns matched for gestational age and birth weight. Sequential measurements of white blood cell count (WBC), platelet count (PC), MPV, interleukin-6 (IL-6) and C-reactive protein (CRP) were compared between groups, and the diagnostic value of each marker for neonatal sepsis was evaluated.

Results A total of 100 patients with neonatal sepsis ( 35 with proven sepsis and 65 with clinical sepsis) and 50 healthy controls were enrolled. A comparison of markers of sepsis obtained at baseline revealed WBC, CRP, IL- 6 and MPV levels to be significantly higher in newborns with sepsis compared to healthy controls $(p=0.01,<0.001$, $<0.001$ and 0.001 , respectively). Mean baseline serum levels of CRP and MPV were significantly higher in Group 1a compared to Group $1 b(p=0.005, p=0.007$, respectively), whereas the difference between group with regards to baseline serum levels of IL- 6 and PC was statistically insignificant ( $\mathrm{p}=0.14, \mathrm{p}=0.28$, respectively).

Conclusions This is the first study to demonstrate a statistically significant difference with regard to baseline MPV values between patients with sepsis (proven or clinical) and healthy controls. We believe that MPV could be a useful marker for the diagnosis of NS.

\section{THE PREDICTIVE VALUES OF MEAN PLATELET VOLUME (MPV) IN THE DIAGNOSIS OF NEONATAL SEPSIS}

doi:10.1136/archdischild-2012-302724.1180

B Aydin, A Zenciroglu, D Dilli, S Erol, E Ozyazici, N Karadag, S Beken, N Okumus. Neonatology, Dr Sami Ulus Maternity and Children's Health and Diseases Training and Research Hospital, Ankara, Turkey

Background and Aim Researches to identify markers with high sensitivity and specificity in the diagnosis of neonatal sepsis are being held in parallel to recent advances in neonatology. In this study, we aimed to determine predictive values of MPV in the diagnosis of neonatal sepsis.

Methods All infants diagnosed with clinical sepsis according to clinical and laboratory findings were included in this prospective study. Blood samples for hemoglobin, hematocrit, number of leukocyte, absolute neutrophyl count (ANC), number of platelet, MPV, CRP, blood culture were obtained from each patient within the first 24 hours of hospitalization. Patients who have positive culture results were accepted as proven sepsis. Patients were separated into three groups as proven sepsis ( $\mathrm{n}=82$ ) (Group-1), clinical sepsis $(\mathrm{n}=64)$ (Group-2) and control group (n=142) (Group-3)

Results Group-1 CRP levels were higher $(\mathrm{p}=0.001)$ and number of platelets were lower $(p=0.001)$ compared with other two groups. Leukocyte, ANC and MPV values were significantly high in Group-1 and Group-2 compared with Group 3 and there was no difference between Group-1 and Group-2 ( $p=0.001$ ). Negative correlation was observed between MPV and platelet levels $(r=-0.24, p=0.001)$ whereas positive correlation was observed between MPV and CRP levels $(r=0.26, p=0.001)$. It was noted that for CRP- Specificity $82 \%$, sensitivity $92 \%$, negative predictive value (NPV) $83 \%$, positive predictive value (PPV) $91 \%$, and for MPV- Specificity $54 \%$, sensitivity $82 \%$, NPV 63\%, PPV 76\%.
Conclusion High serum MPV levels in addition to CRP levels may be helpful in the diagnosis of newborns suspected to have sepsis.

\section{PROCALCITONIN LEVEL AT 24 HOURS OF AGE MAY BE PREDICTIVE FOR TRANSIENT TACHYPNEA OF THE NEWBORN}

doi:10.1136/archdischild-2012-302724.1181

${ }^{1}$ A Annagür, ${ }^{2} \mathrm{H}$ Altunhan, ${ }^{3} \mathrm{R}$ Örs, ${ }^{4 i}$ Mehmetoğlu. ${ }^{1}$ Selcuk University, Selcuklu Medical Faculty, Department of Neonatology, Konya; ${ }^{2}$ Abant Izzet Baysal University, Medical Faculty, Department of Neonatology, Bolu; ${ }^{3}$ Konya University, Meram Medical Faculty, Department of Neonatology; "Konya University, Meram Medical Faculty, Department of Clinical Biochemistry, Konya, Turkey

Background The differentiation of transient tachypnea of the newborn from bacterial pneumonia presents an important diagnostic dilemma in Neonatal Intensive Care Unit.

Aim To evaluate the predictive value of procalcitonin for transient tachypnea of the newborn.

Methods Total 122 babies were included to study. All babies were term. Babies were categorized into three groups: If the baby has prominent grunting after 2. hours of age (Group 1, n=38), if grunting subsided at 2 . hours of age and baby has only tachypnea at 24 hours of age (Group 2, $n=41$ ), if respiratory distress signs minimal or absent at 24 hours of age (Group $3, n=43$ ). In all groups, procalcitonin levels were determined at birth and 24 hours of age.

Results Procalcitonin levels at birth were significantly higher in Group 1 than other groups, but there was no difference between Groups 2 and 3. Procalcitonin levels at 24 hours of age were significantly higher in Group 1 and 2 than Group 3. No difference was found between Group 1 and Group 2 at 24 hours of age. All procalcitonin values in Group 3 were significantly lower than other groups. PCT tresholds for the diagnosis of transient tachypnea of the newborn were $0.49 \mathrm{ng} / \mathrm{ml}$ at birth (sensitivity $59 \%$, specificity $51 \%$ ); and $5.88 \mathrm{ng} / \mathrm{ml}$ at $24 \mathrm{~h}$ of life (sensitivity $80.2 \%$, specificity 90.7\%).

Conclusions Serial procalcitonin measurement at birth and 24 hours of age may be helpful in differentiating between pneumonia and transient tachypnea of the newborn. Larger studies are needed to confirm our preliminary results.

\section{TOTAL OXIDATIVE STATUS, TOTAL ANTI-OXIDATIVE STATUS AND PARAOXONASE-1 LEVELS IN NEONATAL SEPSIS}

doi:10.1136/archdischild-2012-302724.1182

${ }^{1} \mathrm{~A}$ Annagür, ${ }^{2} \mathrm{H}$ Altunhan, ${ }^{3} \mathrm{M}$ Konak, ${ }^{4} \mathrm{~S}$ Kurban, ${ }^{3} \mathrm{R}$ Örs. ${ }^{1}$ Department of Neonatology, Selcuk University, Selcuklu Medical Faculty; ${ }^{2}$ Department of Neonatology, Abant lzzet Baysal University, Medical Faculty; ${ }^{3}$ Department of Neonatology; ${ }^{4}$ Department of Clinical Biochemistry, Konya University, Meram Medical Faculty, Konya, Turkey

Aim Paraoxonase-1 (PON-1) is a calcium dependent glycoprotein enzyme that is found on the high density lipoprotein (HDL) in serum. PON-1 has been shown to protect low-density lipoprotein (LDL) and high-density lipoprotein (HDL) against oxidation and can reduce oxidative stres. In sepsis increases oxidative stres and decreases HDL concentrations. The aim of this study was to evaluate oxidant/anti-oxidant status in neonatal sepsis before and after therapy and to determine whether PON-1 could be used to monitor the treatment of neonatal sepsis.

Method Thirty-five patients with neonatal sepsis and 35 healthy controls were included in the study. PON-1 activities, total oxidant status (TOS), total anti-oxidant status (TAS) groups were measured and an oxidative stres index (OSI) was calculated.

Results Plasma levels of TOS, TAS and OSI were significantly higher in patients with neonatal sepsis before therapy as compared to after treatment $(p<0.000, p<0.000$ and $p<0.000$, respectively), plasma PON-1 level was significantly lower $(p<0.000)$ 
Plasma levels of TOS, TAS and OSI were significantly higher in patients with neonatal sepsis before therapy as compared to the control group ( $p<0.000, p<0.000$ and $p<0.000$, respectively) and plasma PON-1 level was significantly lower $(p<0.000)$. TAS levels in after treatment were significantly higher than in the control group ( $p=0.009$ ), while TOS, OSI and PON-1 levels were similar in after treatment compared to control group $(p=0.0 .078, p=0.597$, $\mathrm{p}=0.086$, respectively).

\section{COMPARISON OF URINARY NEUTROPHIL GELATINASE- ASSOCIATED LIPOCALIN, C-REACTIVE PROTEIN AND PROCALCITONIN IN DIAGNOSIS OF LATE ONSET SEPSIS IN PRETERM NEWBORNS}

doi:10.1136/archdischild-2012-302724.1183

'S Ertuğrul, ${ }^{2} \mathrm{R}$ Örs, ${ }^{3}$ S Kurban. ${ }^{1}$ Department of Neonatology; ${ }^{2}$ Konya University, Meram Medical Faculty; ${ }^{3}$ Department of Clinical Biochemistry, Konya University, Meram Medical Faculty, Konya, Turkey

Objective Urinary neutrophil gelatinase-associated lipocalin (uNGAL) has been suggested as a useful marker in limited recent studies for diagnosis of sepsis in pediatric and adult patients. We aimed to determine the value of uNGAL levels in early diagnosis of late-onset sepsis in preterms, and to compare CRP and PCT.

Materials and Methods Between February - May 2011, preterm infants admitted to NICU between the ages of 7 to 28 days divided into two groups: 24 cases with clinical sepsis (gestational age $32.88 \pm 1.45 \mathrm{w}$ ) and 20 cases as control group (gestational age $33 \pm 1.49 \mathrm{w})$.

Results There is no difference in two groups in terms of demographic features of babies. At 1. and 7. days of treatment in sepsis group, CRP (median:25.09mg/Lvs8.63mg/L),

PCT (median; $17.11 \mathrm{ng} / \mathrm{mlvs} 1.39 \mathrm{ng} / \mathrm{ml}$ )and uNGAL levels were found $45.69 \pm 18.37 \mathrm{ng} / \mathrm{ml}, 7.89 \pm 4.19 \mathrm{ng} / \mathrm{ml}$ respectively. In control group, uNGAL levels were found $5.78 \pm 1.6 \mathrm{ng} / \mathrm{ml}$. We found significant differences CRP, PCT and uNGAL levels between groups. On the seventh day of treatment, CRP, PCT and UNGAL levels significantly decreased.

We found that the sensitivity, specificity, positive and negative predictive values, respectively: for CRP; $58.3 \%, 80 \%, 77.8 \%$ and $61.5 \%$, for PCT; $91.7 \%, 75 \%, 81.5 \%$ and $88.2 \%$, for uNGAL; $91.7 \%$, $100 \%, 100 \%$ and $90.9 \%$.

Conclusion Urinary NGAL seems to be more sensitive and spesific, reliable biomarker than serum CRP and PCT. We believe that uNGAL unlike other biomarkers that does not require a blood sample, non-invasive and non-sterile conditions, with small amounts of urine collection in newborn sepsis might be an ideal biomarker.

\section{PRO-ADRENOMEDULLIN AS A PROGNOSTIC MARKER IN NEONATAL SEPSIS}

doi:10.1136/archdischild-2012-302724.1184

MY Oncel, U Dilmen, 0 Erdeve, R Ozdemir, E Calisici, S Yurttutan, FE Canpolat, SS Oguz, N Uras. Neonatology, Zekai Tahir Burak Maternity Teaching Hospital, Ankara, Turkey

Background and Aims The aim of this study was to investigate the value of pro-adrenomedullin (pro-ADM), as a marker of neonatal sepsis while comparing it with conventional markers of infection in newborns.

Methods Subjects were stratified into three groups; proven sepsis (Group 1a) and clinical sepsis (Group 1b) and the control group (Group 2) consisted of gestational age and birth weight matched newborns. Sequential measurements of white blood cell (WBC) count, C-reactive protein (CRP), interleukin-6 (IL-6) and pro-ADM were compared between groups.

Results A total of 76 patients with neonatal sepsis (31 with proven sepsis and 45 with clinical sepsis) and 52 healthy controls were enrolled. Mean baseline serum levels of CRP, IL-6 and pro-ADM were significantly higher in both Group $1 \mathrm{a}$ and Group $1 \mathrm{~b}$ compared to healthy controls $(p<0.001$ for both). Although mean baseline CRP and IL-6 levels were similar between groups, mean baseline pro-ADM level was higher in the proven sepsis group than the clinical sepsis group $(p<0.001)$.

Conclusion This is the first clinical study to investigate the value of pro-ADM for the diagnosis of proven and clinical sepsis in a newborn cohort including preterm newborns. Use of pro-ADM in combination with other acute phase reactants such as CRP and IL-6 for the diagnosis and follow-up of patients with neonatal sepsis has high sensitivity and specificity.

\section{NEUTROPHILE VOLUME, CONDUCTIVITY AND SCATTER PARAMETERS AND BETTER RESULTS WITH EMMA STATISTICAL PROGRAMIME IN NEONATAL SEPSIS}

doi:10.1136/archdischild-2012-302724.1185

1] Çelik, 'G Demirel, ${ }^{2} \mathrm{D}$ Sukhachev, ${ }^{1} 0$ Erdeve, ${ }^{1,3} \mathrm{U}$ Dilmen. 'Neonatology, Zekai Tahir Burak Maternity Teaching Hospital, Ankara, Turkey; ${ }^{2}$ LabTech LTD, Saint Petersburg, Russia; ${ }^{3 P e d i a t r i c s, ~ Y i l d i r i m ~ B e y a z i t ~ U n i v e r s i t y, ~ F a c u l t y ~ o f ~ M e d i c i n e, ~ A n k a r a, ~ T u r k e y ~}$

Introduction Current hematology analysers can determine cell volume $(V)$, conductivity for internal composition of cell(C) and light scatter for cytoplasmic granularity and nuclear structure(S) and standart deviations.

Method We investigated these parameters in secreening of neonatal sepsis beyond the first day of life. We used LH780 hematological analyzer(Beckman Coulter, Fullerton, CA). We combined these parameters with interleukin-6(IL-6) and C-reactive protein(CRP), and developed models to diagnose sepsis by Effective Modelling of Moleculer Activity(EMMA).

Results A total of 237 newborn, 61 proven sepsis, 108 clinical sepsis and 68 control, were enrolled the study. Mean neutrophil volume $(\mathrm{MNV})$ and volume distribution width(VDW) were found to be statistically increased both in proven and clinical sepsis groups. We developed models using MNV, VDV, IL- 6 and CRP. These models gave more sensitivity and specificity than usage of MNV, VDW, IL-6 and CRP alone.

Conclusion We suggest to use combination of MNV and VDW with markers such as CRP and IL-6, and use diagnostic models created by using EMMA including these markers.

Model 1: Sepsis $=-1.17+0.015^{*}[\mathrm{CRP}]+0.009^{*}[\mathrm{MNV}]$

Model 2: Sepsis $=-1.35+0.0136 *[\mathrm{CRP}]+0.0074 *[\mathrm{MNV}]+0.0123^{*}$

[VDW].

Model 3: Sepsis $=-0.94+0.0043 *[$ IL6 $]+0.011 *[$ CRP $]+0.0069 *[\mathrm{MNV}]$

Table 2. Test results and models' performance of sepsis group

Parameter Cut-off Sens Spec 95\% Confidence Interval

MNV (au) $>157.178 .6481 .630 .807$ to 0.890

VDW (au) $>37.459 .7177 .550 .687$ to 0.789

IL6 $(\mathrm{pg} / \mathrm{mL})>1881.7692 .650 .869$ to 0.945

CRP (mg/dL) >7.5 71.5798 .530 .852 to 0.928

Model $1>0.309988 .7392 .650 .921$ to 0.975

Model $2>0.361587 .7592 .650 .912$ to 0.970

Model $3>0.242995 .8691 .180 .950$ to 0.992

\section{DOES AVAILABILITY OF INTERLEUKIN-6 RESULTS INFLUENCE CLINICAL DECISION MAKING IN NEONATAL SEPSIS?}

doi:10.1136/archdischild-2012-302724.1186

1,2S Babarao, 'L Miall. 'Neonatal Unit, Leeds Teaching Hospitals NHS Trust; ${ }^{2}$ School of Paediatrics, University of Leeds, Leeds, UK

Backround and aims Clinical diagnosis of neonatal sepsis has always been challenging. Recent studies have suggested that 